\title{
ANALISIS PENGARUH KEPUASAN KERJA TERHADAP KINERJA KARYAWAN DAN LOYALITAS PELANGGAN (STUDI KASUS PADA BENGKEL YAMAHA TANGSEL)
}

\author{
Roby Irzal Maulana * \\ 1,2,3 Fakultas Ekonomi Universitas Pamulang, Banten - Indonesia
}

\section{A R T I C L E I N F O \\ Article history: \\ Received 13 April 2018 \\ Received in revised form 13 May 2018 \\ Accepted 05 December 2019 \\ Available online 11 \\ December 2019 \\ Kata Kunci: \\ Kepuasan kerja, kinerja \\ karyawan, loyalitas \\ pelanggan \\ Keywords: \\ Work Satifaction, Worker's performance, Customer's loyalty}

\begin{abstract}
A B S T R A K
Penelitian ini memiliki tujuan untuk menganalisis pengaruh secara parsial: 1). kepuasan kerja terhadap kinerja karyawan, 2). kepuasan kerja terhadap loyalitas pelanggan, 3).kinerja karyawan terhadap loyalitas pelanggan. Jenis penelitian yang digunakan yaitu penelitian survei.

Penelitian ini mengambil lokasi di bengkel Yamaha area Tangerang Selatan yang berjumlah 7 bengkel, penelitian ini menggunakan 90 karyawan teknisi/mekanik dan pelayanan serta 30 pelanggan servis sebagai responden penelitiannya. Pembuktian hipotesis penelitian ini menggunakan analisis regresi linier sederhana. Hasil yang diperoleh dari penelitian ini adalah 1).Kepuasan kerja memiliki pengaruh signifikan yang positif terhadap kinerja karyawan, 2). Kepuasan kerja tidak memiliki pengaruh signifikan terhadap loyalitas pelanggan, 3).Kinerja karyawan memiliki pengaruh terhadap loyalitas pelanggan.
\end{abstract}

Kata kunci: Kepuasan kerja, kinerja karyawan, loyalitas pelanggan

A B S T R A C T

This research has aim to partially analyse the effects: 1) Work satisfaction on worker's performance, 2) work satisfaction on customer loyalty, 3) worker's performance on customer loyalty. The type of research is a survey research.

The research was conducted in Yamaha service station South Tangerang division which amounted to 7 locations, the research used 90 tecnician or mechanic and customer service as wellas 30 service customers as respondents. The hypothesis verification used linier regression analysis. The result was: 1) Work satisfaction has positive significant effect on worker's performance, 2) Work satisfaction has no significant effect on customer's loyalty, 3) Worker's performance has effect on customer's loyalty.

Keywords: Work satisfaction, Worker's performance, Customer's loyalty.

\footnotetext{
* Corresponding author.

E-mail : : robyirzalmaulana@gmail.com (Roby Irzal Maulana)

$10.23887 /$ ekuitas.v7i2.13880
} 


\section{Pendahuluan}

Persaingan bisnis jasa perbengkelan khususnya di daerah kota Tangerang Selatan sangat ketat, masing-masing bengkel memiliki strategi tersendiri untuk memenangkan konsumen atau pelanggan. Berbagai cara yang ditempuh oleh setiap bengkel untuk memenangkan persaingan memang berbeda, tetapi pada dasarnya mereka menekankan pada kualitas pelayanan untuk mendapatkan konsumen yang puas dan loyal. Loyalitas pelanggan dapat diartikan sebagai pembelian berulang terhadap produk/ jasa yang di lakukan konsumen pada perusahaan. Menurut Griffin (2003) loyalitas pelanggan lebih mengacu pada wujud perilaku dari unit-unit pengambilan keputusan untuk melakukan pembelian secara terus menerus terhadap barang/jasa suatu perusahaan yang dipilih. Jadi kualitas bengkel menjadi kunci memenangkan persaingan.

Banyaknya usaha jasa bengkel yang berdiri menjadi pesaing bagi bengkel resmi sepeda motor khususnya merek Yamaha. Dalam kondisi yang demikian, keunggulan dalam pelayanan serta kemampuan teknisi menjadi pilihan yang menentukan bagi pelanggan. Masyarakat cenderung lebih memilih menservis sepeda motor pada bengkel yang lebih dekat, murah dan cepat. Banyak dari konsumen menganggap semua bengkel menjual suku cadang yang sama dan memiliki kualitas teknisi yang sama pula dengan bengkel resmi Yamaha. Maka dari itu PT Yamaha Motor Indonesia harus memiliki strategi yang unggul untuk mengimbangi munculnya usaha-usaha bengkel servis yang tidak sesuai dengan standar perusahaan.

Kinerja karyawan merupakan salah satu cara untuk memperoleh kesetiaan atau loyalitas pelanggan. Kinerja dapat didefinisikan sebagai hasil karya atau hasil kerja seorang karyawan dalam melaksanakan pekerjaannya. Kinerja karyawan dapat timbul karena adanya kepuasan karyawan dalam bekerja. Kepuasan kerja merupakan perasaan puas yang dirasakan oleh karyawan dalam bekerja. Penelitian ini bermaksud untuk melanjutkan penelitian sebelumnya yang dilakukan oleh Indrawati (2013) dengan objek penelitian pada rumah sakit swasta di Denpasar. Perbedaan penelitian ini dengan penelitian sebelumnya terletak pada variabel kepuasan konsumen yang diganti menjadi loyalitas pelanggan. Alasan penggantian variabel ini karena, mengutip pernyataan Griffin (2003) kepuasan pelanggan diperlukan untuk kesuksesan bisnis, kepuasan pelanggan tidak cukup untuk membangun atau membentuk basis pelanggan yang loyal. Tingkat kepuasan yang tinggi belum tentu menghasilkan pembelian berulang dan peningkatan penjualan. Oleh karena itu penelitian ini mengambil judul "Analisis Pengaruh Kepuasan Kerja Terhadap Kinerja Karyawan Dan Loyalitas Pelanggan".

\section{Metode}

Jenis penelitian yang dilakukan adalah penelitian survey, yaitu penelitian dengan mengambil sampel dari suatu populasi dan menggunakan kuisioner sebagai alat pengumpulan data yang pokok (Arikunto, 2010). Objek Penelitian, Objek pada penelitian ini adalah menganilisis karyawan dan pelanggan pada bengkel Yamaha area Tangerang Selatan. (1) Populasi, Populasi dalam penelitian ini yaitu seluruh karyawan teknisi, petugas, pelayanan dan pelanggan service berjumlah 120 orang pada bengkel resmi PT Yamaha Motor Indonesia di area Tangerang Selatan dan seluruh pelanggan servis bengkel. (2) Sampel dan Teknik Sampling, dalam Penelitian ini menggunakan dua sampel. Pertama, seluruh karyawan teknisi 
petugas, pelayanan dan pelanggan service menggunakan teknik sampling sensus yang berjumlah 120 pada bengkel Yamaha Kedua, yaitu pelanggan bengkel Yamaha menggunakan teknik sampling purposive dengan persyaratan: (a) pelanggan dengan usia minimal 17 tahun (minimal pelajar SMA); (b) pelanggan melakukan servis sebanyak 2 kali atau lebih terbebas dari masa servis gratis; (c) Kepemilikan sepeda motor atas nama sendiri, orang tua, dan orang lain (kerabat/saudara, motor yang dibeli bekas dan masih atas nama pemilik lama). Untuk menentukan jumlah sampel pelanggan menggunakan rumus dari Umar (2002) yaitu:

$$
n=\frac{1}{4}\left[\frac{z a / 2}{e}\right]^{2}
$$

Keterangan:

$\mathrm{n}=$ Ukuran sample yang diduga

$\mathrm{Z}=$ Confidence coefficient

$\mathrm{e}=$ Standar error

Dalam penelitian ini nilai dari Confidence coefficient (z) adalah 95\% dalam tabel bernilai 1,96. Standar error yang diterima (e) adalah $10 \%$.

$$
n=\frac{1}{4}\left[\frac{1,96}{0,10}\right]^{2}=96,04=96 \text { (pembulatan) }
$$

Dengan demikian, ukuran sampel minimal yang akan digunakan dalam penelitian ini adalah 96 responden pelanggan. Namun untuk mengantisipasi kemungkinan adanya kuesioner yang tidak kembali, tidak lengkap/rusak, peneliti akan mengambil sebanyak 120 responden pelanggan. (4) Definisi operasional variabel adalah penarikan batasan yang lebih menjelaskan ciri-ciri spesifik yang lebih substantive dari suatu konsep. Tujuannya agar peneliti dapat mencapai suatu alat ukur yang sesuai dengan hakikat variabel yang sudah didefinisikan konsepnya, maka peneliti harus memasukkan proses atau operasionalnya alat ukur yang akan digunakan untuk kuantifikasi gejala atau variabel yang ditelitinya.

(a) Variabel ( X ) Kepuasaan Kerja dapat didefinisikan sebagai perasaan positif terhadap suatu pekerjaan, yang merupakan dampak atau hasil evaluasi dari berbagai aspek pekerjaan tersebut, khususnya pada bagian teknisi bengkel dan petugas pelayanan pada bengkel Yamaha area Tangerang Selatan.Indikator Kepuasan Kerja pada bengkel Yamaha area Tangerang Selatan adalah sebagai berikut; Pertama The Work it Self (pekerjaan itu sendiri), pekerjaan tersebut menarik bagi karyawan yang melaksanakan. Kedua Pay, Semua pendapatan yang diterima dari pekerjaan sebagai teknisi/petugas pelayanan. Ketiga Growth and Upword Mobility kesempatan karyawan untuk meningkatkan jabatan lebih tinggi (promosi). Keempat Supervision pengawas yang mendorong dan membantu karyawan dalam bekerja, Co-Workes kerja sama dan dukungan dari rekan kerja. Kelima Attitude Toward Work sikap baik/kesan terhadap pekerjaannya.

(b) Variabel (Y1) Kinerja Karyawan Kinerja adalah perilaku nyata yang ditampilkan karyawan teknisi dan pelayanan sebagai prestasi kerja yang dihasilkan oleh karyawan tersebut sesuai dengan perannya dalam bengkel. Ada 6 kriteria dasar atau dimensi untuk mengukur kinerja, yaitu; Pertama Kuantitas (Quantity) terkait dengan seberapa banyak teknisi menservis sepeda motor pada satu hari kerja dengan baik. kedua Kualitas (Quality) hasil jasa yang memuaskan pelanggan bengkel. ketiga Ketepatan waktu (Timeliness) ketepatan waktu karyawan teknisi dan pelayanan menyelesaikan pekerjaannya. 
Keempat Efektivitas biaya (Cost Effectiveness) ketepatan dalam penggunaan sumber perusahaan seperti suku cadang, teknologi dan material. Kelima Kebutuhan akan pengawasan (Need for Supervision) mendapat dukungan dari atasan. Keenam Hubungan antar perseorangan (Interpersonal Impact) hubungan dan kerja kerja sama antar sesama karyawan dalam bekerja.

(c) Variabel (Y2) Loyalitas Pelanggan merupakan komitmen untuk menservis sepeda motor kembali di masa yang akan datang meskipun dipengaruhi oleh situasi dan keadaan pasar yang dapat menyebabkan berpindahnya servis sepeda motor ke bengkel lain. Terdapat beberapa Indikator loyalitas pelanggan yaitu; Pertama Repeat Purchase, pelanggan melakukan servis sebanyak 2 kali atau lebih. Kedua Reward, selain pelanggan datang untuk servis, mereka akan membeli produk yang di jual oleh bengkel. Ketiga Recommendation, merekomendasikan produk dan jasa bengkel kepada orang yang dikenal (teman/saudara). Keempat Merasa puas keseluruhan dan percaya dengan pelayanan di bengkel. Kelima Refuse, kebal terhadap tarikan pesaing atau tidak terpengaruh untuk servis di bengkel lain.

\section{Hasil dan pembahasan}

Hasil penelitian yang di dapat berupa respon rate dengan menyebar kuesioner sebanyak 120 (untuk karyawan dan pelanggan). Kuesioner kembali dengan terisi lengkap sebanyak 110. Dan data tersebut dilakukan analisis dengan uji asumsi kelasik yang terdiri dari; pertama Uji Normalitas, Hasil uji statistik non-parametrik Kolmogorov-Smirnov menyatakan model 1 (kepuasan kerja terhadap kinerja karyawan) bernilai 0,904, model 2 (kepuasan kerja terhadap loyalitas pelanggan) bernilai 0,403 dan model 3 (kinerja karyawan terhadap loyalitas pelanggan) bernilai 0,947, maka dapat disimpulakan bahwa data penelitian telah terdistribusi normal, karena nilai asymp.sig lebih dari 0,05. Kedua, Uji heteroskedastisitas dilakukan dengan uji glejser, hasil uji model 1 (kepuasan kerja terhadap kinerja karyawan) bernilai 0,910, model 2 (kepuasan kerja terhadap loyalitas pelanggan) bernilai 0,345, dan model 3 (kinerja karyawan terhadap loyalitas pelanggan) bernilai 0,603. Nilai signifikansi keseluruhan lebih dari 0,05 yang artinya model regresi diasumsikan tidak terdapat heteroskedastisitas.

Setelah melakukan uji asumsi kelasik maka akan dilanjutkan dengan uji koefisien korelasi dengan beberapa model yaitu; Model 1 (kepuasan kerja terhadap kinerja karyawan) bernilai 0,367 dengan signifikansi $<0,05(0,000)$. Model 2 (kepuasan kerja terhadap loyalitas pelanggan) bernilai -0,014 dengan signifikansi $>0,05(0,441)$ dan model 3 (kinerja karyawan terhadap loyalitas pelanggan) bernilai 0,185 dengan signifikansi $<0,05(0,024)$.

Berdasarkan hasil koefisien regresi model persamaan regresinya didapatkan pengujian hipotesis sebagai berikut; Model 1 Y=13,242+0,332X1, Model 2 Y=21,650-0,013X1, Model 3 Y=17,042+0,202Y1. Berdasarkan hasil pengujian uji t, ada dua model yang hipotesisnya dterima yaitu model 1 ( kepuasan kerja terhadap kinerja karyawan ) karena t hitung $>\mathrm{t}$ tabel yaitu 4,043 >1,652, dan model model 2 (kinerja karyawan terhadap loyalitas pelanggan) karena $t$ hitung $>t$ tabel yaitu 1,924 $>1,663$.

Berdasarkan pengujian hipotesis pertama, diketahui bahwa variabel kepuasan kerja memiliki $t$ hitung sebesar 4,043 dan $t$ tabel sebesar 1,663 dengan demikian $t$ hitung $>t$ tabel yaitu 4,043>1,663maka Ho ditolak dan Ha diterima, berarti variabel kepuasan kerja secara parsial berpengaruh terhadap kinerja karyawan. Dengan demikian hipotesis pertama yang berbunyi kepuasan kerja secara parsial berpengaruh terhadap kinerja karyawan diterima. 
Penelitian ini konsisten dengan penelitian Indrawati (2013) yaitu kepuasan kerja karyawan berpengaruh signifikan positif terhadap kinerja karyawan namun dengan berbeda objek yaitu di rumah sakit swasta di Denpasar. Hasil penelitian ini juga mendukung penelitian dari Wahyudi (2011) bahwa faktor-faktor kepuasan kerja berpengaruh positif signifikan terhadap kinerja karyawan dengan objek Universitas Muhammadiyah Jakarta di Kota Tangerang Selatan.

Berdasarkan pengujian hipotesis kedua, diketahui bahwa variabel kepuasan kerja memiliki t hitung $-0,126$ sebesar dan $\mathrm{t}$ tabel sebesar 1,642 dengan demikian $\mathrm{t}$ hitung $\leq \mathrm{t}$ tabel yaitu $-0,126<1,642$ maka Ho diterima dan Ha ditolak, berarti variabel kepuasan kerja secara parsial tidak berpengaruh terhadap loyalitas pelanggan. Dengan demikian hipotesis kedua yang berbunyi kepuasan kerja secara parsial berpengaruh terhadap loyalitas pelanggan ditolak.

Penelitian lainnya yang mengkaji mengenai kepuasan kerja terhadap loyalitas pelanggan dilakukan oleh Sukotjo (2008) yang berjudul pengaruh kepuasan kerja terhadap kualitas pelayanan, kepuasan konsumen dan loyalitas pelanggan pada perguruan tinggi swasta (PTS) di Jawa Timur yang memiliki hasil kepuasan kerja berpengaruh negatif signifikan terhadap loyalitas pelanggan. Dengan adanya perbedaan objek penelitian dan metode analisis dapat mengakibatkan hasil penelitian yang berbeda.

Objek penelitian bengkel dan perguruan tinggi termasuk bidang jasa, tetapi terdapat perbedaan kepuasan kerja diantara kedua tempat tersebut. Dilihat dari faktor pendapatan/gaji kedua profesi ini, pendapatan karyawan perguruan tinggi lebih besar daripada karyawan bengkel, sehingga kepuasan kerja mereka mendorong munculnya loyalitas pelanggan.

Berdasarkan pengujian hipotesis ketiga, diketahui bahwa variabel kinerja karyawan memiliki t hitung 1,924 dan $\mathrm{t}$ tabel sebesar 1,654 sehingga diketahui $\mathrm{t}$ hitung $>\mathrm{t}$ tabel yaitu 1,924 >1,654 maka Ho ditolak dan Ha diterima, ini berarti variabel kinerja karyawan berpengaruh terhadap variabel loyalitas pelanggan. Hipotesis yang berbunyi kinerja karyawan secara parsial berpengaruh terhadap loyalitas pelanggan diterima.

Penelitian ini medukung penelitian dari Djati dan Darmawan (2005) dengan judul pengaruh kinerja karyawan terhadap kepuasan, kepercayaan dan kesetiaan pelanggan dengan objek usaha retail. Penelitian tersebut menyatakan bahwa variabel kinerja karyawan berpengaruh tidak langsung terhadap variabel kesetiaan pelanggan.

\section{Simpulan dan saran}

Berdasarkan hasil analisis dan pembahasan yang telah diuraikan, maka dapat ditarik kesimpulan; pertama Kepuasan kerja secara parsial berpengaruh terhadap kinerja karyawan. Kedua Kepuasan kerja secara parsial tidak berpengaruh terhadap loyalitas pelanggan. Ketiga Kinerja karyawan secara parsial berpengaruh terhadap loyalitas pelanggan.

Saran yang di dapat dari analisis dan pembahasan yang telah diuraikan adalah 1. Berdasarkan hasil analisis dan pembahasan, pihak bengkel disarankan lebih memperhatikan dan mempertimbangkan adanya kenaikan pendapatan/gaji karyawan, agar kepuasan kerja karyawan lebih meningkat. 2. Untuk mempertahankan pelanggan, pihak bengkel diharapkan memberikan kinerja layanan yang memuaskan, fasilitas bengkel yang bagus, diskon untuk servis/ pembelian suku cadang. 3. Kinerja karyawan dapat ditingkatkan dengan cara membina hubungan komunikasi yang baik dengan sesama karyawan dan atasan. 
4. Penelitian selanjutnya dapat menambah variabel kepuasan konsumen, kepercayaan konsumen dan kualitas pelayanan sebagaivariabel intervening sehingga diharapkan model penelitian selanjutnya akan lebih baik. 5. Hal yang dapat direkomendasikan bagi peneliti mendatang terkait dengan hasil penelitian ini adalah dapat menambah kajiannya dengan memperbanyak jumlah sampel penelitian, sehingga hasilnya menjadi akurat. Serta teknik pengambilan sampel merata dari pagi hingga sore agar karakteristik pelanggan merata. 6. Penelitian selanjutnya juga disarankan untuk memilih usaha bengkel Yamaha sebagai objeknya, karena penelitian ini perlu digali lebih mendalam dan penelitian pada bengkel Yamaha masih sedikit.

\section{Daftar Rujukan}

Arikunto, S. 2010. Prosedur penelitian suatu pendekatan praktik. Jakarta: Rineka Cipta.

Djati, S. Pantja dan Didit Darmawan.2005.Jurnal Pengaruh Kinerja Karyawan Terhadap Kepuasan, Kepercayaan, dan Kesetiaan Pelanggan (diakses Juni 2015).

Griffin, Jill. 2003. Customer loyalty: Menumbuhkan dan mempertahankan kesetiaan pelanggan. Jakarta. Penerbit Erlangga.

Hariandja, Marihot Tua Efendi.2009. Manajemen sumber daya manusia. Jakarta: PT Grasindo.

Hasibuan, Malayu S.P. 2007. Manajemen Sumber Daya Manusia. Jakarta: PT Bumi Aksara.

Indrawati,Ayu Desi. 2013. Jurnal Pengaruh Kepuasan kerja terhadap kinerja karyawan dan kepuasan pelanggan pada Rumah Sakit Swasta Di kota Denpansar.

Kotler dan Keller.2009. Manajemen Pemasaran.Jakarta: Penerbit Erlangga.

Mangkunegara.2012. Evaluasi kinerja sumber daya manusia.Bandung:PT Refika Aditama.

Wahyudi. 2011. Jurnal pengaruh faktor-faktor kepuasan kerja terhadap kinerja karyawan Universitas Muhammadiyah Jakarta di Kota Tangerang Selatan.

Robbins dan Judge. 2008. Perilaku Organisasi. edisi 12. Salemba empat: Jakarta.

Rivai dan Sigala. 2011. Manajemen sumber daya manusia untuk perubahan. Bandung: PT Remaja Rosda Karya.

Sugiyono. 2007. Metode Penelitian Bisnis.Cetakan kesepuluh. Bandung: Alfabeta.

Sukotjo, Hendri. 2011. Jurnal Kepuasan kerja terhadap kualitas pelayanan, kepuasan pelanggan dan loyalitas pelanggan pada PTS di Jawa Timur.(diakses Juni 2015).

Suwatno dan Priansa, Donni Juni.2011. Manajemen Sumber Daya Manusia untuk Perusahaan, dari teori ke praktek. Rajawali Pers:Jakarta.

Umar,Husein. 2002. Riset pemasaran dan perilaku konsumen. PT Gramedia Pustaka: Jakarta. 